Publié dans : Journal of Performance of Constructed Facilities, Vol. 31, Issue 3 (Octobre 2016) https://doi.org/10.1061/(ASCE)CF.1943-5509.0000960

\title{
Methods for shear strengthening of thick concrete slabs
}

Mathieu Fiset ${ }^{1}$, Josée Bastien $^{2}$ and Denis Mitchell ${ }^{3}$

\section{Abstract:}

4 This paper presents different strengthening techniques to improve the shear capacity of existing

5 thick concrete slab structures that were constructed without shear reinforcement. Reinforcing

6 bars are installed into vertical drilled holes and anchored with epoxy adhesive to increase the

7 shear capacity. Experiments on retrofitted beams, representing slab strips, showed that all of the

8 strengthening techniques investigated resulted in increased shear capacities. The shear failure

9 mechanisms of the strengthened beams showed that, as expected, current evaluation methods for

10 elements with conventional, well-anchored stirrups can lead to an overestimation of the shear

11 capacities. The efficiency of the strengthening techniques is strongly influenced by the

12 performance of the end anchorage of the drilled-in bars. The effectiveness of the epoxy-bonded

13 bars is a function of their embedded length and they can, in some cases, debond before they

14 reach their yield strength. By using the maximum bar spacing required by the Canadian Highway

15 Bridge Design Code or the AASHTO-LRFD design specifications, bonded shear reinforcing bars

16 may debond and offer poor performance. A maximum transverse reinforcement spacing criterion

17 is therefore suggested for the added bonded bars.

\footnotetext{
${ }^{1} \mathrm{Ph}$. D. Candidate, Research Center on Concrete Infrastructures, Dept. of Civil Engineering, Université Laval., Quebec city, QC, Canada, G1V 0A6 (Corresponding author). E-mail: Mathieu.Fiset.1@ulaval.ca

${ }^{2}$ Professor, Research Center on Concrete Infrastructures, Dept. of Civil Engineering, Université Laval., Quebec city, QC, Canada, G1V 0A6. E-mail: Josee.Bastien@gci.ulaval.ca

3 Professor, Dept. of Civil Engineering and Applied Mechanics, McGill University. Montréal, QC, Canada. E-mail: Denis.Mitchell@mcgill.ca
} 
20 Concrete thick slab bridges typically have spans ranging from $6 \mathrm{~m}$ to $25 \mathrm{~m}$ (20' to $80^{\prime}$ ') with a

21 structural slab thickness of $300 \mathrm{~mm}$ to $1500 \mathrm{~mm}$ (12 in. to 60"). For this simple structural

22 system, the thick slab is designed to carry all loads and therefore no support beams (girders) are

23 required. For the design of thick concrete slabs, it is often assumed that the shear capacity

24 provided by the concrete is sufficient to resist the shear and therefore, no shear reinforcement is

25 required. On September 30 ${ }^{\text {th }}$, 2006, the Concorde overpass (Laval, Quebec, Canada) collapsed,

26 killing five people and injuring six others (Fig. 1). Even though the original design complied

27 with standards at the time of construction, a shear failure in the cantilever region of the

28 supporting concrete thick slab led to collapse (Johnson et al. 2007; Mitchell et al. 2011). This

29 shear failure occurred in the $1200 \mathrm{~mm}$ (48 in.) thick slab that did not contain any shear

30 reinforcement. The shear failure was very brittle and lead to the sudden collapse of one-half of

31 the overpass structure. For the Concorde overpass collapse, the investigation has shown that

32 concrete degradation with time resulted in the propagation of inclined cracks, followed by a

33 brittle shear failure. That tragic event raised questions concerning the safety of many aging thick

34 concrete slab bridges without shear reinforcement. Moreover, the investigation showed that the

35 provision of the minimum amount of shear reinforcement recommended by the 2014 Canadian

36 Highway Bridge Design Code S6 (CHBDC) (CSA 2014a) would have prevented the Concorde

37 overpass collapse. Because of the deficiencies in shear of this type of construction, practical

38 methods incorporating shear reinforcing bars into thick concrete slabs have gained wide interest.

39 Some shear strengthening methods have already been studied on narrow beams. The addition of

40 near surface mounted rods (De Lorenzis and Nanni 2001; Dias and Barros 2008) and the addition

41 of external carbon fiber reinforced plastic (FRP) laminates (Adhikary and Mutsuyoshi 2006; 
42 Teng et al. 2009) have been proven successful to increase shear capacity. However, the

43 anchorage of such shear reinforcement on either side of a concrete beam section raised question

44 of their efficiency on the full width of wide structural elements like thick slab bridges. On one

45 hand, thin slabs strengthened in shear with bonded inclined drilled-in rods have shown their

46 efficiency to increase punching shear capacity (Fernández Ruiz et al. 2010). On the other hand,

47 very few studies were performed on the strengthening of existing thick slabs where the well

48 known "size effect" (Godat et al. 2010; Collins et al. 2008) will influence the shear capacity.

49 This paper presents shear strengthening techniques that can be used on existing concrete thick

50 slab structures to improve the shear capacity (Fig. 2). The loading tests performed as well as the

51 comparison between shear capacities of concrete thick slab strips (beams) strengthened and

52 unstrengthened in shear are presented. The techniques investigated consist of placing reinforcing

53 bars into pre-drilled vertical holes with epoxy bonding. The performance of this system has been

54 examined through experimental tests. The responses of the strengthened beams are compared to

55 tested reference beams, with conventional stirrups and without stirrups.

\section{Description of Post-Installed Shear Strengthening methods}

57 Fig. 2 shows the installation of two strengthening techniques. The first method (Fig. 2a) consists

58 of filling drilled holes with high-performance epoxy adhesive to bond the full length of steel bars

59 to the concrete. For this case, the holes are drilled from the top surface and the bars are inserted

60 into the epoxy-filled holes from the top. The alternative method (Fig. 2b) consists of introducing

61 the epoxy-bonded shear reinforcement from both the top and bottom slab faces, in order to

62 provide longer bar embedded lengths near the bottom surface.

\section{Experimental Program}

64 Two series of three point loading tests were performed for a total of 15 beams representing thick 
65 slab strips (beams) which were designed to experience shear failures. All simply supported

66 beams (4000 mm span) have a rectangular cross section of $610 \mathrm{~mm}$ width, $b_{w}$, and constant

67 heights, $h$, of $450 \mathrm{~mm}$ or $750 \mathrm{~mm}$. Details of the beams are presented in Table 1 and Fig. 3.

68 Three reference specimens, (U1, U2, and U3), without shear reinforcement were also tested.

69 These beams are not shown in Fig. 3 but they have the same overall dimensions and flexural

70 reinforcement as the shear strengthened beams B1, B2 and B3.

71 Description of the $1^{\text {st }}$ test series

72 Beam specimens U1, U2 and U3, and their companion beams with post-installed epoxy bonded

73 bars B1, B2 and B3 were designed to study the effectiveness of the bonded shear reinforcement

74 on the beam shear capacities. The spacing ratio, equal to the spacing of the bars, $s_{v}$, divided by

75 the effective shear depth, $d_{v}$, of the post-installed shear reinforcement is close to the maximum

76 allowed by North American Standards $\left(k_{v, \max }=s_{v, \max } / d_{v}=0.75\right.$ and 0.80 for CHBDC S6 (CSA

77 2014a) and AASHTO (2012) respectively). Beams B1 and B3 were strengthened using 15M

78 reinforcing bars whereas beam B2-1 and B2-2 were strengthened with $10 \mathrm{M}$ reinforcing bars

79 (refer to Table 2 for the bar area, $A_{b}$, and the bar diameter, $d_{b}$ ). These post-installed bars were

80 introduced into 14.3 and $19.1 \mathrm{~mm}$ diameter holes for the $10 \mathrm{M}$ and $15 \mathrm{M}$ bars, respectively, and

81 bonded to the concrete with epoxy adhesive (Fig. 2a). The longitudinal reinforcement ratio $\rho$ is

82 presented in Table 1 and, for this first series of beams, 25M bars were used for longitudinal

83 tension reinforcement.

84 Description of the $2^{\text {nd }}$ test series

85 Specimens of the second series, which were all strengthened in shear, provide results to compare

86 different reinforcing methods. Beams B4, B5 and S1 have transverse reinforcement spaced such

87 that the ratio $k_{v}=s_{v} / d_{v}$ was 0.61 . Beam $\mathrm{S} 1$ is a typical reinforced concrete beam with $15 \mathrm{M}$ 
88 conventional stirrups. Beams B4 and B5 were strengthened with vertical 15M epoxy-bonded

89 bars post-installed into $19.1 \mathrm{~mm}$ diameter holes. The post-installed bars in beam B4 were

90 installed from the top face of the beam, whereas they were installed from both top and bottom

91 faces for beam B5 (Fig. 3b). For this series, 30M bars were used for longitudinal tension

92 reinforcement in the beams.

\section{$93 \quad$ Material Properties}

94 The average compressive strengths of the concrete, $f_{c}^{\prime}$, presented in Table 1 were determined at

95 an age at which the beams were tested. The maximum aggregate size of the concrete, $a_{g}$, was 19

$96 \mathrm{~mm}$ for all specimens and the concrete density, $\gamma_{c}$, is presented in Table 1 . The steel reinforcing

97 bars yielding strength, $f_{y}$, and ultimate strength, $f_{u}$, are given in Table 2. For all bars, the

98 Young modulus, $E_{s}$, was taken as $200 \mathrm{GPa}$. A commercially available epoxy adhesive was used

99 for the bonded anchorage. The bond strength, $\tau_{b}$, of the epoxy adhesive was estimated as

100 (Fernández Ruiz et al 2010, ETA 2013):

101

$$
\tau_{b}=18.7\left(\frac{f_{c}^{\prime}}{20}\right)^{0.1} \quad \text { in MPa units }
$$

102 The development length, $\ell_{d}$, of the bonded bars with epoxy adhesive can therefore be evaluated

103 from Eq. (2). It varies between 90 and $97 \mathrm{~mm}$ for the $15 \mathrm{M}$ bars and is about $62 \mathrm{~mm}$ for the $10 \mathrm{M}$

104 bars used for beam B2.

105

$$
\ell_{d}=\frac{d_{b}}{4} \frac{f_{y}}{\tau_{b}}
$$

\section{Testing procedure and measurements}

107 All beams were tested under three point loading. Fig. 4 shows the experimental setup for a 750

$108 \mathrm{~mm}$ deep beam loaded at mid-span. For the $450 \mathrm{~mm}$ deep beams, the loading is applied at one- 
109 third of the span only (three point loading). The loading was applied at a rate of $10 \mathrm{~mm} / \mathrm{h}$ and

110 beam deflections were measured at the loading location. Strain gages (red points in Fig. 3) were

111 used to measure strains in the shear and longitudinal reinforcing bars. LVDTs (Linear Variable

112 Differential Transformers) were installed on the side faces of the beams at mid-depth to measure

113 shear crack width development. A crack comparator was used to measure crack widths. After the

114 tests, concrete core samples were extracted from the beams and some beam sections were cut to

115 examine the anchorage quality of the bonded bars.

116 For the second test series, after the occurrence of shear failure, the beams were strengthened with

117 steel clamping devices as shown on the right hand side of Fig. 4. This allows the reloading of a

118 beam $(40 \mathrm{~mm} / \mathrm{h})$ until the failure of the other half of the beam (left hand side of Fig. 4). To

119 distinguish between loading and reloading tests of the same beam, these reloaded beams are 120 identified as beams "R", such as: B4-1R, B5-1R and S1-1R.

\section{$121 \quad$ Test Results}

122 Table 1 provides a summary of the test results. In this table, the values of the experimental shear

123 force, $V_{\text {exp }}$, (including effects of beam self-weight) and the beam deflection, $\delta_{\text {exp }}$, measured at

124 the loading location (see Fig. 4) are given at failure. The applied shear versus $\delta_{\text {exp }}$ and the critical

125 crack width, $w$, are shown in Fig. 5. Due to failure of the data recording system, no data is 126 available for beam B1-2. Fig. 6 shows the cracking patterns for the half-portion of the beam 127 where the failure occurred. The critical failure cracks are shown with a bold line while the lighter 128 lines show other cracks having smaller crack widths.

\section{Behavior of slab strips}

130 Unstrengthened beams (Beams U1, U2 and U3)

131 As expected, beam specimens U1, U2 and U3 had only minor diagonal cracking up to the 
132 maximum failure load. Shear failure occurred after the sudden formation of a critical inclined

133 crack and a horizontal splitting crack along the longitudinal reinforcement. These failures

134 occurred suddenly, with little or no warning. The shear strengths of beams U1, U2 and U3 were

135324,291 and $342 \mathrm{kN}$, respectively. The post-failure resistances were about 100 and $160 \mathrm{kN}$ for

136 beam specimens U1 and U2, respectively. Beams U3 showed almost no post-failure resistance.

137 These tests demonstrate the danger associated with the sudden shear failure mode of concrete

138 thick slab structures without shear reinforcement.

139 Beam with conventional stirrups (Beam S1)

140 The main critical shear crack leading to failure was visible on both sides of beam S1 at a shear of

141 about $525 \mathrm{kN}$ and this critical crack progressed slowly during the remaining loading. Beam S1-1

142 failed at a central deflection of $10.7 \mathrm{~mm}$ and a corresponding shear of $726 \mathrm{kN}$. With a post-

143 failure resistance of $500 \mathrm{kN}$ (decrease of 35\%), beam S1-1 exhibited a larger residual shear

144 capacity than the other beams. The reloaded beam test S1-1R was stopped before the shear

145 failure because of the yielding of the steel clamped assemblies used on the other half span. The

146 shear capacity of the beam test S1-1R is therefore higher than $809 \mathrm{kN}$ (see Table 1).

147 Beams with bonded shear reinforcing bars (Beams B1, B2, B3, B4)

148 The beams strengthened with drilled-in, bonded shear reinforcing bars exhibited rapid 149 propagation of a wide diagonal crack with a significant decrease of the beam stiffness. For 150 example, for beam B4-1, it can be observed in Fig. 5 that increasing the shear force by $34 \mathrm{kN}$

151 (508 to $542 \mathrm{kN}$ ) resulted in an increase in the central deflection by $1.9 \mathrm{~mm}$ (4.6 to $6.5 \mathrm{~mm}$ ). For 152 this beam, a large crack of width $1.5 \mathrm{~mm}$ propagated from the support to the loading location, 153 crossing reinforcing bars R3 and R4 (see Fig. 6 for bar locations). For comparison, the diagonal 154 crack width in beam $\mathrm{S} 1-1$ at $525 \mathrm{kN}$ was $0.3 \mathrm{~mm}$ and no cracking was visible crossing 
155 reinforcing bars at location R3. For beams B1 and B3, a large critical diagonal crack appeared at 156425 and $412 \mathrm{kN}$, respectively. Thereafter, new diagonal cracks appeared during the loading and

157 the maximum shear capacity of beams B1, B3 and B4 were 471, 498 and $756 \mathrm{kN}$, respectively.

158 By comparison with the unstrengthened beam specimens U1 and U3, the shear capacity of 159 strengthened beams B1 and B3 increased by about $45 \%$ and their deflections at failure increased 160 by $79 \%$ and $146 \%$, respectively.

161 For beam B2-1, no shear crack was visible before the maximum shear capacity of $288 \mathrm{kN}$ was 162 reached at a $6.8 \mathrm{~mm}$ deflection. At this load level, a diagonal crack appeared suddenly and the 163 shear force was maintained below the maximum capacity, at a shear of $285 \mathrm{kN}$, until a sudden 164 loss of the beam capacity, at a deflection of $8.4 \mathrm{~mm}$. For beam B2-2, the shear force was 165 maintained after the propagation of the critical diagonal crack at a shear of $289 \mathrm{kN}$. The failure 166 of beam B2-2 occurred at a displacement of $9.8 \mathrm{~mm}$ and a shear of $315 \mathrm{kN}$. Compared with the 167 other beams with drilled-in bonded bars, beam B2 showed no additional shear cracking after the 168 propagation of the large diagonal crack. While the strengthening of this beam resulted in an 169 increase in shear capacity of only $4 \%$, the maximum deflection is $25 \%$ higher than those 170 measured in the unstrengthened beams U2-1 and U2-2.

171 As expected, the failure modes of beams B1, B2 and B3, with bonded reinforcing bars, are less

172 brittle: beams B1, B2 and B3 showed signs of their pending failure with large diagonal cracks 173 and higher deformation and post failure capacities than their unstrengthened companion 174 specimens U1, U2 and U3. Likewise, beam B4 showed a similar post failure capacity of $450 \mathrm{kN}$ 175 and a deflection capacity of $12.0 \mathrm{~mm}$ as beam S1 with conventional stirrups (500 kN and 10.7 $176 \mathrm{~mm})$.

177 Beam with overlapped bonded shear reinforcing bars (Beam B5) 
178 Beam B5 with overlapped bonded bars shows more diagonal cracks than the other beams with

179 drilled-in bonded bars. Initially, the progression of most of the diagonal cracks was controlled in

180 the overlapped portion of the shear reinforcing bars. As the load increased, new diagonal cracks

181 appeared in this region. Before the failure, the development of a wide diagonal crack suggested

182 an imminent shear failure. The failure of beam B5-1 is very brittle and the concrete crushed in

183 the compression zone at a deflection of $15.6 \mathrm{~mm}$ and a shear of $942 \mathrm{kN}$. The reloaded beam B5-

184 1R (tested after clamping the failed end) may have been weakened by the very brittle failure of

185 the beam B5-1 and the crushing of the compression zone resulting in a lower shear capacity of

$186823 \mathrm{kN}$. Therefore, the experimental capacity obtained for the reloaded beam B5-1R was not

187 used for comparison purposes.

188 Observation of internal cracking

189 After testing, the beams were dissected to enable inspection of the internal shear cracking and to

190 see the intersection of this cracking with the added shear reinforcing bars. Fig. 7 shows a view of

191 the inside of beam B5-1R that was strengthened with overlapping bars drilled-in from the top

192 and bottom and then bonded with epoxy. The gaps between the bottom end of bar R2t and the

193 top end of bars R3t and R4t indicate that slippage of the bars had occurred due to debonding.

194 This slippage was most apparent at locations where the shear crack resulted in short embedment

195 lengths of the drilled-in bars.

\section{Behavior of shear reinforcing bars}

197 Fig. 8 shows the average of the measured strain in two stirrup legs, $\varepsilon_{s v}$, versus the central 198 deflection of the beams. The yield strain $\left(\varepsilon_{y}=f_{y} / E_{s}\right)$ of the shear reinforcing bars is shown as a 199 dashed horizontal line. Table 3 shows the embedded lengths and the distance between the strain 200 gage and the main diagonal crack $\left(L_{t c}\right)$. For beam S1-1, the values of $L_{t c}$ for stirrups R2, R3 and 
$201 \mathrm{R} 4$ are 128, 30 and $133 \mathrm{~mm}$, respectively. The bar embedded length $\ell_{e}$ for the drilled-in bars is

202 taken as the shortest length between the main diagonal crack and the bar extremity. The

203 calculated bar development length, determined from Eq. (2), is shown. The maximum stress in

204 the bar layer $f_{s v, c a l c}$ is determined according to the bond strength determined from Eq. (1) and is

205 limited by the bar yielding strength. A linear stress-strain relationship, given by Eq. (4) is used to

206 determine the experimental bar stress $f_{s v, e x p}$. The maximum values are given in Table 3 according

207 to the maximum bar strain shown in Fig. 8.

$$
\begin{gathered}
f_{s v, c a l c}=\frac{4 \tau_{b} \ell_{e}}{d_{b}} \leq f_{y} \\
f_{s v, \text { exp }}=E_{s} \varepsilon_{s v} \leq f_{y}
\end{gathered}
$$

210 As seen in Fig. 8, strains in the bonded shear reinforcing bars only occurred after the shear 211 cracking load was reached. For beam B5-1 (Fig. 8), the propagation of two diagonal cracks 212 resulted in increased bar strains at a deflection of about $2.5 \mathrm{~mm}$. The first diagonal crack 213 intercepted the bars at location R2b (see Fig. 6) and its propagation stopped, while the second 214 crack crossed the bars at locations R3b, R3t and R4t. Some beams with shear reinforcement 215 failed shortly after the yielding of one set of added reinforcing bars. The force that can be 216 developed in each bar is a function of the bar embedment length defined by the location of the 217 diagonal crack. When the diagonal crack intercepts a reinforcing bar close to one of its ends, the 218 resulting embedded length $\ell_{e}$ could be shorter than $\ell_{d}$ and therefore debonding would occur 219 without reaching $f_{y}$. For example, it can be seen in Table 3 and Fig. 8 that the diagonal crack 220 occurred near the very end of the bar at location R2 of beam B1-1 resulting in a short embedded 221 length and consequently, this bar debonded.

222 In interpreting the strain readings, it is important to consider the fact that the reinforcing bar 
223 strain will be at its highest at a crack location. Thus, even if $\ell_{e} \geq \ell_{d}$, it can be seen in Fig. 8 and

224 Table 3 that some of the measured strains in the shear reinforcing bars were below $\varepsilon_{y}$. However,

225 it can be expected that these bars had reached their yield strain at crack locations.

226 The debonding of some bonded bars can also be seen in Fig. 8. For example, the bars at location

227 R2 in beam B1-1 experienced increasing strains until a maximum of 1659 microstrain $\left(f_{\text {seep }}=\right.$

$228332 \mathrm{MPa})$ at $\delta_{\text {epp }}=9.9 \mathrm{~mm}$. This was followed by decreasing strains until 652 microstrain $\left(f_{\text {s.epp }}=\right.$

$229130 \mathrm{MPa})$ at the beam failure $\left(\delta_{\mathrm{epp}}=13.7 \mathrm{~mm}\right)$. It can be seen in Table 3 that the maximum

230 predicted bar stress $f_{\text {s.all }}$ of $242 \mathrm{MPa}$ from Eq. (3) underestimates the experimental value of 332

231 MPa.

232 For beam S1-1 with conventional stirrups, the bars at locations R2 and R3 reached their yield

233 strength at a central deflection of $5.7 \mathrm{~mm}$. This is followed by a large increase in the strain of the

234 bars at location $\mathrm{R} 4$, reaching a maximum strain 2040 microstrain (408 MPa) at a deflection of

$2359.9 \mathrm{~mm}$. While the strain gages on the bar at location R4 showed strains below the yield strain, it

236 is possible that this reinforcement yielded at the crack location. For this case, $L_{t c}=133 \mathrm{~mm}$ and

237 hence these bars may have reached $f_{y}$. Compared with beam B4, the conventional stirrup legs in

238 beam S1 are well anchored at both extremities. They cannot slip like the drilled-in bonded bars

239 and therefore, they offer better control of the diagonal cracking. Thus, if the diagonal crack

240 crosses a stirrup near the extremities of the stirrup legs, they are still capable of developing their 241 yield capacity.

\section{Comparison with strength predictions and discussion}

243 The predicted shear capacity $V_{\text {calc }}$ was determined at a distance $d_{v}$ from the edge of the loading 244 plate. The shear design provisions of the Canadian Standards Association (CSA) standard A23.3 
245 (CSA 2014b), the Canadian Highway Bridge Design Code S6 (CSA 2014a) and the AASHTO 246 specifications (AASHTO 2012) are based on the Modified Compression Field Theory (Collins et

247 al. 1996; Bentz and Collins 2004). These requirements define the nominal shear strength 248 attributed to the concrete, $V_{c}$, and the shear resistance provided by the shear reinforcement, $V_{s}$.

249 The equations from CSA standard A23.3 (CSA 2014b), expressed in SI units, are given below 250 for the nominal shear resistance (i.e., material resistance factors $\phi_{c}=\phi_{s}=1$ ).

$$
V_{c}=\beta \sqrt{f_{c}^{\prime}} b_{w} d_{v} \quad \text { in MPa units }
$$

$$
\beta=\left(\frac{0.4}{1+1500 \varepsilon_{x}}\right)\left(\frac{1300}{1000+s_{z e}}\right) \mathrm{mm}
$$

$$
V_{s}=A_{v} f_{y} \frac{d_{v} \cot \theta}{s_{v}}
$$

254 Where $A_{v}$ is the area of transverse reinforcement within a distance $s_{v}$ and $\beta$ is the ability of the 255 diagonally cracked concrete to resist shear by tension stiffening and aggregate interlock (Eq. (6) 256 ). It is a function of the longitudinal strain, $\varepsilon_{x}$, at mid-depth of the beam and the equivalent 257 horizontal crack spacing, $s_{z e}$. For concrete members without transverse reinforcement, $258 s_{z e}=35 d_{v} /\left(16+a_{g}\right)$ (mm units). For members containing at least the minimum amount of 259 transverse reinforcement, the equivalent crack spacing parameter $s_{z e}$ is taken as $300 \mathrm{~mm}$ (12 in).

260 This minimum amount of transverse reinforcement is determined from Eq. (8), where $C=0.060$ 261 for both the CSA S6 code (2014a) and the CSA standard A23.3 (2014b), while $C=0.083$, in 262 MPa units for AASHTO specifications (2012).

$$
A_{v} \geq C \frac{\sqrt{f_{c}^{\prime}}}{f_{y}} s_{v} b_{w}
$$


264 The angle of principal compression in the concrete, $\theta$, with respect to the longitudinal member

265 axis can be used to determine the number of effective transverse reinforcing bars, $n_{v}$, resisting 266 shear.

$$
n_{v}=\frac{d_{v} \cot \theta}{s_{v}}
$$

Unstrengthened beams (Beams U1, U2 and U3)

269 The calculated shear strength $V_{\text {calc }}$ and the experimental shear capacity $V_{\text {exp }}$ are given in Table 1.

270 The concrete nominal shear stress at failure $\left(v_{c}=V_{\text {exp }} /\left(b_{w} d_{v}\right)\right)$ shows the size effect

271 phenomenon for beams without shear reinforcement. With an effective shear depth, $d_{v}$, of 333

$272 \mathrm{~mm}$ and $359 \mathrm{~mm}$ respectively, beams U1 and U2 experienced a shear stress at failure of 1.59

$273 \mathrm{MPa}$ and 1.33 $\mathrm{MPa}$, respectively, whereas the shear stress at failure of the deepest beam

274 specimens U3 $\left(d_{v}=629 \mathrm{~mm}\right)$ failed at a lower shear stress of $0.89 \mathrm{MPa}$. A good correlation

275 between experimental results and calculated values is achieved with the calculated shear

276 capacity, $V_{\text {calc }}$, for the beams without shear reinforcement being close to $V_{\text {exp }}$ (average

$\left.277 \quad V_{\text {calc }} / V_{\text {exp }}=1.00\right)$.

278 Beam with conventional stirrups (Beam S1)

279 For both tests on the beams S1-1 (tests S1 for the first loading and S1-1R for the reloading) with

280 stirrups, the predictions are very close to the experimental shear capacities. The average ratio

$281 V_{\text {calc }} / V_{\text {exp }}$ is 1.05 while the predicted amount of shear reinforcing bars crossed by the diagonal

282 crack $n_{v}$ is 2.35 . These results are in good agreement with the cracking patterns shown in Fig. 6,

283 where the main diagonal crack crossed 3 and 2 bar locations for beams S1-1 and S1-1R, 284 respectively. 
286 For the beam specimens with epoxy bonded shear reinforcing bars, the predicted shear strengths 287 provided by the bonded shear reinforcing bars are determined from Eq. (7). The experimental 288 cracking patterns showed that the main diagonal crack crossed 2 reinforcing bar locations for 289 beams B2, B3 and B4-1 and 3 locations for beams B1 and B4-1R. Comparing these observations 290 with the values of $n_{v}$ indicates reasonable predictions of the amount of transverse reinforcement 291 resisting shear. However, with the assumption that the added bars yield, the shear capacities of 292 beams B1, B2 and B3 are overestimated $\left(V_{\text {calc }} / V_{\text {exp }}=1.28,1.42\right.$ and 1.41, respectively) while for 293 beam B4 $V_{\text {calc }} / V_{\text {exp }}=1.07$.

294 Previous measurements showed that bonded bars can fail by debonding before reaching $f_{y}$ when $295 \ell_{e}<\ell_{d}$ and hence some adjustments are necessary to account for this important effect. As shown 296 in Table 3, all the bonded shear reinforcing bars of beams B4 were able to fully develop their 297 yield strength and therefore, beam B4-1 and B4-1R had a similar behavior to the beam with 298 stirrups and the predicted shear capacity is close to the experimental shear capacity. For beams 299 B1, B2 and B3, a number of bonded bars have partially contributed to the shear capacity due to 300 the fact that a crack crossing a bar within $\ell_{d}$ may lead to the debonding of the bar. As illustrated 301 in Fig. 9, the length $\ell_{y}$ along a bar where a crossing diagonal crack would allow the 302 development of $f_{y}$ in the bar can be defined as:

$$
\ell_{y}=\ell_{b a r}-2 \ell_{d}
$$

304 Where $\ell_{b a r}$ is the bar length and $\ell_{d}$ is the bar development length defined by Eq. (2). A diagonal 305 crack is more likely to cross within $\ell_{y}$ for small spacings and for long bonded bars. The bar 
efficiency ratio in shear $\eta$ can be defined as follows:

$$
\eta=\frac{\ell_{y}}{d_{v}}
$$

By comparing beams with similar bar development lengths, the bars used for beam B1 and B2

$309\left(\ell_{b a r}=345 \mathrm{~mm}\right)$ are shorter than the bars used for beams B3 $\left(\ell_{b a r}=645 \mathrm{~mm}\right)$ and B4 $\left(\ell_{b a r}=660\right.$

$310 \mathrm{~mm}$ ). According to the $\ell_{d}$ values presented in Table 3 , the bar efficiency ratio $\eta$ of these beams

311 are $0.45,0.64,0.72$ and 0.77 , respectively. The longer bars used for beams B3 and B4 are

312 therefore more efficient than the bars used for beams B1 and B2.

313 A small shear reinforcement spacing ratio $k_{v}=s_{v} / d_{v}$ also enables the diagonal crack to cross a

314 larger number of shear reinforcing bars within the yielding length, $\ell_{y}$. For beams B1, B2 and

315 B3, the $s_{v} / d_{v}$ values were close to the maximum allowed by standards ( 0.75 for the S6 code

316 (CSA 2014a) and 0.80 for AASHTO (2012)). Consequently, the main shear cracks intercepted

317 two bar locations near their extremities. However, for beam B4, the smaller ratio $k_{v}$ of 0.61

318 allowed the main diagonal crack to cross two bar locations within $\ell_{y}$, with one being intercepted

319 at its mid-height.

320 Beam with overlapped bonded shear reinforcing bars (Beam B5)

321 For the shear capacity of beam B5, the overlapped area of shear reinforcing bars is neglected

$322\left(A_{v}=400 \mathrm{~mm}^{2}\right)$. The experimental cracking patterns showed that the main diagonal crack

323 crossed 2 reinforcing bar locations, which is similar to the prediction of $n_{v}=2.35$. However, the

324 prediction underestimates the shear capacity for beam B5-1 $\left(V_{\text {calc }} / V_{\text {exp }}=0.85\right)$. This

325 underestimation can be explained by the overlapping of the bonded bars. The lap length of 300

$326 \mathrm{~mm}$ is longer than twice the development length ( $2 \ell_{d}=182 \mathrm{~mm}$ in the epoxy-filled hole). The bar 
327 efficiency ratio $\eta$ is 1.03 for each pair of overlapped bars and hence the effective bar capacity is

328 higher than $A_{v} f_{y}$. As shown in Table 3 for beam B5-1, the yield force of bars R3b was fully

329 developed while the bars R3t reached a maximum stress of $192 \mathrm{MPa}\left(0.426 A_{v} f_{y}\right)$ (Table 3).

330 Thus, the two bars R3t and R3b are able to carry a total of $256 \mathrm{kN}\left(1.426 A_{v} f_{y}\right)$ instead of $179 \mathrm{kN}$

$331\left(A_{v} f_{y}\right)$ assuming $A_{v}=400 \mathrm{~mm}^{2}$. In addition, beam B5 has shown a larger number of diagonal

332 cracks in the overlapped bar region than the other beams. The reduction of the crack spacing in

333 the lapped region would likely increase $V_{c}$ for beam B5.

\section{Maximum spacing of added bonded bars}

335 The experimental results of the beams with added bonded shear reinforcing bars have shown that

336 the maximum bar spacing needs to be smaller than that required in current codes for stirrups.

337 According to current codes (CSA S6 (2014a), CSA A23.3 (2014b) and AASHTO (2012)),

338 stirrups shall be spaced so that every line inclined at an angle $\theta$ to the axis of the member and

339 extending toward the reaction from mid-depth to the member longitudinal flexural tension

340 reinforcement shall be crossed by at least one line of effective shear reinforcement. Over the full

341 shear depth, $d_{v}$, of the beam, a minimum of two stirrups intercepting the inclined compression

342 field are therefore required. This enables the development of the compression field between two

343 transverse bars carrying tension. The maximum spacing ratio $k_{v, \max }$ and the maximum spacing

$344 s_{v, \max }$ of transverse reinforcement can therefore be determined as follow:

$$
k_{v, \text { max }}=\frac{s_{v, \text { max }}}{d_{v}}=\frac{1}{2 \tan \theta}
$$

346 For example, for an angle $\theta$ of $34^{\circ}, k_{v, \max }=0.75$ as defined by the Canadian Highway Bridge

347 Design Code S6 (CSA 2014a). For bonded bars, the location of the crack determines the bar 
348 embedded length and the bar capacity. For a diagonal crack crossing within the bar yielding

349 length $\ell_{y}$, the transverse reinforcement can reach its yield strength. For cracks crossing within

350 length $\ell_{d}$, partial contribution of the bar is expected. By assuming a constant bond strength

351 along the development length of the bars, the tensile stress $f_{s v}$ that can be developed in the

352 transverse bonded reinforcement can be determined by Eq. (13), where $y$ is the smallest

353 distance measured from the bar extremity (see Fig. 9).

$$
f_{s v}=\frac{4 \tau_{b} y}{d_{b}} \leq f_{y}
$$

355 The resulting tensile stress distribution in the bonded bars is illustrated in Fig. 9. To meet the 356 maximum spacing requirement, this figure shows how the bonded bars can develop $A_{v} f_{y}$ in both 357 lower and upper parts of the beam. The maximum spacing of transverse bonded reinforcement 358 can therefore be determined by Eq. (14).

$$
s_{v, \text { max }}=k_{v, \text { max }} \ell_{y} \leq k_{v, \text { max }} d_{v}
$$

360 Note that using $k_{v, \text { max }} \ell_{y}<s_{v}<k_{v, \text { max }} \ell_{\text {bar }}$ results in partial development of the vertical bars. By 361 taking into account the efficiency ratio $\eta$ from Eq. (11), the maximum spacing ratio of bonded 362 transverse reinforcement can be rewritten as:

$$
\frac{s_{v, \max }}{d_{v}}=\eta k_{v, \max }
$$

364 Where $\eta$ is defined by Eq.(11) and is not greater than 1. Because $\ell_{d}$ is a constant for a given 365 bonded bar, its efficiency ratio increases as the depth of the slab increases. For shallower slabs, it 366 would be required to use mechanical anchorages at the extremities of the added bars to avoid 367 debonding, or to use inclined bonded bars to increase their embedded length. 
368 From Eq. (15) and $k_{v}=s_{v} / \ell_{y}, k_{v}=1.60,1.18,1.04,0.79$ and 0.61 for beams B1, B2, B3, B4 and

369 B5 respectively. Beams B4 and B5 are the only ones meeting the standards requirement $\left(k_{v, \max }=\right.$

$370 \quad 0.75$ and 0.80 for the CSA S6 code (2014a) and AASHTO specifications (2012), respectively)

371 while, the transverse bar spacing of the other beams enables partial development of the bonded

$372 \operatorname{bars}\left(k_{v, \text { max }} \ell_{y}<s_{v}<k_{v, \text { max }} \ell_{\text {bar }}\right)$. Consequently, the responses of beams B4 and B5 were similar to

373 the beam with stirrups while the shear capacities of the other beams were lower than the ones

374 predicted based on specifications for members with conventional stirrups.

\section{Conclusions}

376 Experiments were carried out on thick concrete slab strips (beams) to evaluate the efficiency of

377 different shear strengthening techniques. The shear capacities were compared to the predictions

378 using current design provisions for elements with or without conventional transverse

379 reinforcements (stirrups). The experimental results showed that:

380 1. The strengthening techniques resulted in increased shear and deflection capacities 381 compared to beams without shear reinforcement.

382 2. The beams with added epoxy-bonded bars experienced a rapid propagation of the critical 383 diagonal crack. This resulted in a decrease of stiffness compared with the beams 384 reinforced with conventional stirrups.

385 3. Short embedded bonded bars $\left(\ell_{e}<\ell_{d}\right)$ failed by debonding at the ends of the bars before 386 reaching $f_{y}$ and hence adjustments are needed to accurately predict the strength by using 387 current code provisions that assume yielding of the transverse reinforcement.

388 4. Closely spaced longer bonded bars are more likely to result in yielding of the added 389 epoxy-bonded bars. In such cases, beams exhibit a similar behavior to beams with 
stirrups and the predictions using current code provisions accurately predict the shear

$391 \quad$ strength.

392 5. For added epoxy bonded bars, the maximum spacing required by the current codes for 393 conventional stirrups can result in an overestimation of the shear capacity of up to $48 \%$.

394 Therefore, a maximum spacing requirement for transverse bonded bars has been $395 \quad$ proposed.

396 6. The predicted shear capacities using current code provisions for the beams respecting the 397 proposed maximum spacing requirement of the transverse bonded reinforcement (Eq. 398 (15)) agree well with the experimental results.

\section{Acknowledgments}

400 The research reported in this paper was made possible by funding from the Natural Sciences and 401 Engineering Research Council of Canada (NSERC, CREATE-INFRA) and the "Fonds de 402 Recherche du Québec - Nature et Technologies" (FRQNT). The authors also acknowledge the 403 contributions of Philippe Provencher and Benoit Cusson who performed the beam tests. The 404 experiments were carried out in the structures laboratory at Université Laval. 


\section{Notation}

407 The following symbols are used in this paper:

$408 A_{s} \quad=$ area of longitudinal reinforcement on the flexural tension side;

$409 A_{v} \quad=$ area of shear reinforcement within a distance $s_{v}$;

$410 \quad b_{w} \quad=$ beam web width;

$411 d=$ effective depth to the main tension reinforcement;

$412 d_{b} \quad=$ reinforcing bar diameter;

$413 d_{v} \quad=$ effective shear depth, taken as the greater of $0.9 d$ and $0.72 h$;

$414 \quad E_{s} \quad=$ modulus of elasticity of steel;

$415 f_{c}^{\prime} \quad=$ concrete cylinder compressive strength;

$416 f_{s v} \quad=$ stress in transverse reinforcement;

$417 f_{y} \quad=$ yield strength of reinforcement;

$418 k_{v} \quad=$ spacing ratio of transverse reinforcement;

$419 \ell_{b a r} \quad=$ length of added shear reinforcing bar;

$420 \quad \ell_{d} \quad=$ bar tension development length;

$421 \quad \ell_{e} \quad=$ bar embedded length;

$422 \quad \ell_{y} \quad=$ bar yielding length, equal to $\ell_{b a r}-2 \ell_{d}$;

$423 n_{v} \quad=$ number of effective transverse reinforcing bars;

$424 s_{v} \quad=$ spacing of transverse reinforcement taken along the member longitudinal axis;

$425 s_{z e} \quad=$ equivalent longitudinal crack spacing; 
$426 V_{c} \quad=$ shear resistance attributed to the concrete;

$427 V_{s} \quad=$ shear resistance provided by shear reinforcement;

$428 \quad \beta \quad=$ factor accounting for shear resistance of cracked concrete;

$429 \gamma_{c} \quad=$ concrete density $\left(\mathrm{kN} / \mathrm{m}^{3}\right)$;

$430 \quad \varepsilon_{s v} \quad=$ strain in transverse reinforcement;

$431 \quad \varepsilon_{x} \quad=$ longitudinal strain at mid-depth of the member;

$432 \quad \eta \quad=$ bonded bar efficiency ratio in shear;

$433 \theta=$ angle of diagonal compressive stresses to the longitudinal axis of the member;

$434 \rho=$ longitudinal reinforcement ratio, equal to $A_{s} / b_{w} d$ for a rectangular beam; and

$435 \tau_{b} \quad=$ bond strength of the adhesive (MPa). 


\section{References}

438 Adhikary, B. B., and Mutsuyoshi, H. (2006). "Shear strengthening of reinforced concrete beams 439 using various techniques.” Constr. Build. Mater., 20(6), 366-373.

440 American Association of State Highway and Transportation Officials (AASHTO). (2012). 441 “AASHTO-LRFD bridge design specifications.” Washington, D.C.

442 Bentz, E.C. and Collins, M.P., "Development of the 2004 CSA A23.3 Shear provisions for 443 reinforced concrete," Can. J. Civ. Eng., 33(5), 521-534.

444 Canadian Standards Association (CSA). (2014a). "Canadian highway bridge design code." CSA 445 S6-14, Mississauga, ON, Canada.

446 Canadian Standards Association (CSA). (2014b). "Design of concrete structures." CSA A23.3447 14, Mississauga, ON, Canada.

448 Collins, M. P., Bentz, E. C., and Sherwood, E. G. (2008). "Where is shear reinforcement 449 required? Review of research results and design procedures.” ACI Struct. J., 105(5), 590-599.

450 Collins, M.P., Mitchell, D., Adebar, P. and Vecchio, F.J. (1996), “A general shear design 451 method", ACI Struct. J., 93 (1), 36-45.

452 De Lorenzis, L., and Nanni, A. (2001). "Shear strengthening of reinforced concrete beams with 453 near-surface mounted fiber-reinforced polymer rods.” ACI Struct. J., 98(1), 60-68.

454 Dias, S. J. E., and Barros, J. A. O. (2008). "Shear strengthening of T cross section reinforced 455 concrete beams by near-surface mounted technique.” J. Compos. Constr., 10.1061/(ASCE) 1090456 0268. (2008)12:3(300).

457 European Technical Approval (ETA). (2013). “Injection system hilti HIT-RE 500.” ETA458 04/0027, Deutsches Institut für Bautechnik, Berlin, Germany.

459 Fernández Ruiz, M., Muttoni, A., and Kunz, J. (2010). "Strengthening of flat slabs against 
460 punching shear using post-installed shear reinforcement.” ACI Struct. J., 107(4), 434-442.

461 Godat, A., Qu, Z., Lu, X. Z., Labossière, P., Ye, L. P., and Neale, K.W. (2010). "Size effects for 462 reinforced concrete beams strengthened in shear with CFRP strips." J. Compos. Const., 463 10.1061/(ASCE)CC.1943-5614.0000072.

464 Johnson, P. M., Couture, A., and Nicolet, R. (2007). "Commission of inquiry into the collapse of 465 a portion of the de la Concorde overpass." Library and National Archives of Quebec. $466\langle$ http://www.cevc.gouv.qc.ca/UserFiles/File/Rapport/report_eng.pdf $\rangle$ (Jan. 2015).

467 Mitchell, D., Marchand, J., Croteau, P., and Cook, W. D. (2011). “Concorde overpass collapse:

468 structural aspects.” J. Perform. Constr. Facil., 10.1061/(ASCE)CF.1943-5509.0000183.

469 Teng, J. G., Chen, G. M., Chen, J. F., Rosenboom, O. A., and Lam, L. (2009). "Behavior of RC 470 beams shear strengthened with bonded or unbonded FRP wraps." J. Compos. Const., 471 10.1061/(ASCE) CC.1943-5614.0000040. 
Table 1. Main properties of tested specimens and comparison to the predicted shear capacities.

\begin{tabular}{c|c|c|c|c|c|c|c|c|c|c|cc|c|c|c|c|c|c|c|c|c|c|c|}
$\begin{array}{c}\text { Beam } \\
\text { designation }\end{array}$ & $\begin{array}{c}\text { Strengthening } \\
\text { technique }\end{array}$ & $\mathrm{mm}$ & $\mathrm{mm}$ & $\%$ & $\mathrm{~mm}$ & $\mathrm{~mm}^{2}$ & $\mathrm{~mm}$ & & $\mathrm{kN} / \mathrm{m}^{3}$ & $\mathrm{MPa}$ & $\mathrm{kN}$ & $\mathrm{mm}$ & $\mathrm{kN}$ & & $V_{\text {calc }} / V_{\text {exp }}$ \\
\hline
\end{tabular}

\section{Strengthened slabs}

\begin{tabular}{|c|c|c|c|c|c|c|c|c|c|c|c|c|c|c|c|c|c|c|}
\hline B1 & $\begin{array}{l}1 \\
2 \\
\end{array}$ & Bonded & 450 & 370 & 3.10 & 333 & 400 & 240 & 0.72 & $\begin{array}{l}22.3 \\
22.3 \\
\end{array}$ & $\begin{array}{l}31.7 \\
33.5 \\
\end{array}$ & $\begin{array}{c}471 \\
- \\
\end{array}$ & $\begin{array}{c}13.7 \\
- \\
\end{array}$ & $\begin{array}{l}212 \\
217 \\
\end{array}$ & $\begin{array}{l}2.03 \\
2.03 \\
\end{array}$ & $\begin{array}{l}390 \\
389 \\
\end{array}$ & $\begin{array}{l}602 \\
606 \\
\end{array}$ & $\begin{array}{c}1.28 \\
- \\
\end{array}$ \\
\hline $\mathrm{B} 2$ & $\begin{array}{l}1 \\
2 \\
\end{array}$ & Bonded & 450 & 399 & 2.05 & 359 & 200 & 260 & 0.72 & $\begin{array}{l}22.5 \\
22.6 \\
\end{array}$ & $\begin{array}{l}34.3 \\
35.5 \\
\end{array}$ & \begin{tabular}{|l|}
288 \\
315 \\
\end{tabular} & $\begin{array}{l}8.4 \\
9.8 \\
\end{array}$ & $\begin{array}{l}248 \\
251 \\
\end{array}$ & $\begin{array}{l}2.05 \\
2.05 \\
\end{array}$ & $\begin{array}{l}179 \\
179 \\
\end{array}$ & $\begin{array}{l}426 \\
429 \\
\end{array}$ & $\begin{array}{l}1.48 \\
1.36 \\
\end{array}$ \\
\hline B3 & $\begin{array}{l}1 \\
2 \\
\end{array}$ & Bonded & 750 & 699 & 1.17 & 629 & 400 & 470 & 0.75 & $\begin{array}{l}22.7 \\
22.4 \\
\end{array}$ & $\begin{array}{l}34.0 \\
37.2 \\
\end{array}$ & \begin{tabular}{|l|}
491 \\
505 \\
\end{tabular} & $\begin{array}{l}12.3 \\
11.4 \\
\end{array}$ & $\begin{array}{l}349 \\
361 \\
\end{array}$ & $\begin{array}{l}1.82 \\
1.82 \\
\end{array}$ & $\begin{array}{l}350 \\
349 \\
\end{array}$ & $\begin{array}{l}699 \\
710 \\
\end{array}$ & $\begin{array}{l}1.42 \\
1.40 \\
\end{array}$ \\
\hline B4 & $\begin{array}{c}1 \\
1 \mathrm{R}\end{array}$ & Bonded & 750 & 694 & 1.65 & 625 & 400 & 380 & 0.61 & 22.6 & 34.5 & $\begin{array}{l}743 \\
769 \\
\end{array}$ & $\begin{array}{l}12.0 \\
14.4 \\
\end{array}$ & $\begin{array}{l}389 \\
389 \\
\end{array}$ & $\begin{array}{l}2.34 \\
2.34 \\
\end{array}$ & $\begin{array}{l}420 \\
420 \\
\end{array}$ & $\begin{array}{l}809 \\
809 \\
\end{array}$ & $\begin{array}{l}1.09 \\
1.05 \\
\end{array}$ \\
\hline B5 & $\begin{array}{c}1 \\
1 \mathrm{R} \\
\end{array}$ & $\begin{array}{c}\text { Overlapped } \\
\text { Bonded }\end{array}$ & 750 & 694 & 1.65 & 625 & 400 & 380 & 0.61 & 22.6 & 32.6 & $\begin{array}{l}942 \\
823 \\
\end{array}$ & $\begin{array}{l}15.6 \\
26.3 \\
\end{array}$ & $\begin{array}{l}380 \\
380 \\
\end{array}$ & $\begin{array}{l}2.35 \\
2.35 \\
\end{array}$ & $\begin{array}{l}421 \\
421 \\
\end{array}$ & \begin{tabular}{|l|}
801 \\
801 \\
\end{tabular} & $\begin{array}{l}0.85 \\
0.97 \\
\end{array}$ \\
\hline $\mathrm{S} 1$ & $\begin{array}{c}1 \\
1 \mathrm{R} \\
\end{array}$ & Stirrups & 750 & 694 & 1.65 & 625 & 400 & 380 & 0.61 & 22.2 & 33.3 & $\begin{array}{l}726 \\
809 \\
\end{array}$ & $\begin{array}{l}10.7 \\
27.1 \\
\end{array}$ & $\begin{array}{l}383 \\
383 \\
\end{array}$ & $\begin{array}{l}2.35 \\
2.35 \\
\end{array}$ & $\begin{array}{l}421 \\
421 \\
\end{array}$ & $\begin{array}{l}804 \\
804 \\
\end{array}$ & $\begin{array}{l}1.11 \\
0.99 \\
\end{array}$ \\
\hline Uns & & ed slabs & & & & & & & & & & & & & & $\begin{array}{l}\text { erage } \\
\text { toV }\end{array}$ & & $\begin{array}{l}1.22 \\
0.17 \\
\end{array}$ \\
\hline
\end{tabular}

\begin{tabular}{|c|c|c|c|c|c|c|c|c|c|c|c|c|c|c|c|c|c|c|}
\hline U1 & $\begin{array}{l}1 \\
2 \\
\end{array}$ & none & 450 & 370 & 3.10 & 333 & - & - & - & $\begin{array}{l}22.3 \\
22.3\end{array}$ & $\begin{array}{l}31.1 \\
33.7\end{array}$ & $\begin{array}{l}324 \\
324\end{array}$ & $\begin{array}{l}7.6 \\
7.7\end{array}$ & $\begin{array}{l}285 \\
293 \\
\end{array}$ & - & - & $\begin{array}{l}285 \\
293\end{array}$ & $\begin{array}{l}0.88 \\
0.90\end{array}$ \\
\hline U2 & $\begin{array}{l}1 \\
2\end{array}$ & none & 450 & 399 & 2.05 & 359 & - & - & - & $\begin{array}{l}22.5 \\
22.6\end{array}$ & $\begin{array}{l}34.9 \\
35.7\end{array}$ & $\begin{array}{l}278 \\
304\end{array}$ & $\begin{array}{l}6.9 \\
7.7\end{array}$ & $\begin{array}{l}287 \\
289\end{array}$ & - & - & $\begin{array}{l}287 \\
289\end{array}$ & $\begin{array}{l}1.03 \\
0.95\end{array}$ \\
\hline U3 & $\begin{array}{l}1 \\
2\end{array}$ & none & 750 & 699 & 1.17 & 629 & - & - & - & $\begin{array}{l}22.4 \\
22.7\end{array}$ & $\begin{array}{l}35.8 \\
33.2\end{array}$ & $\begin{array}{l}343 \\
341\end{array}$ & $\begin{array}{l}5.0 \\
4.6\end{array}$ & $\begin{array}{l}389 \\
379\end{array}$ & - & - & $\begin{array}{l}389 \\
379\end{array}$ & $\begin{array}{l}1.13 \\
1.11\end{array}$ \\
\hline & & & & & & & & & & & & & & & \multicolumn{3}{|c|}{ Average } & $\begin{array}{l}1.00 \\
0.11\end{array}$ \\
\hline
\end{tabular}

Note: beams U1, U2, B1 and B2 are loaded at one-third span, while other beams are loaded at mid-span. To distinguish between loading and reloading tests of the same beam, reloaded beams are identified "R". For all beams, width $b_{w}=610 \mathrm{~mm}$

${ }^{a}$ This beam did not experience shear failure. The capacity was limited by the steel clamped assemblies used to strengthen beam S1-1 
Table 2. Steel reinforcing bars properties

\begin{tabular}{llllll}
\hline $\begin{array}{l}\text { Test } \\
\text { Series }\end{array}$ & $\begin{array}{l}\text { Bar } \\
\text { Designation }\end{array}$ & $\begin{array}{l}d_{b} \\
(\mathrm{~mm})\end{array}$ & $\begin{array}{l}A_{b} \\
\left(\mathrm{~mm}^{2}\right)\end{array}$ & $\begin{array}{l}f_{y} \\
(\mathrm{MPa})\end{array}$ & $\begin{array}{l}f_{u} \\
(\mathrm{MPa})\end{array}$ \\
\hline \multirow{3}{*}{$1 \mathrm{st}$} & $10 \mathrm{M}$ & 11.3 & 100 & 436 & 632 \\
\cline { 2 - 6 } & $15 \mathrm{M}$ & 16.0 & 200 & 480 & 690 \\
\cline { 2 - 6 } & $25 \mathrm{M}$ & 25.2 & 500 & 468 & 660 \\
\hline \multirow{2}{*}{ 2nd } & $15 \mathrm{M}$ & 16.0 & 200 & 448 & 633 \\
\cline { 2 - 6 } & $30 \mathrm{M}$ & 29.9 & 700 & 508 & 668 \\
\hline
\end{tabular}


Table 3. Bonded bars embedded length and bar stress

\begin{tabular}{|c|c|c|c|c|c|c|c|}
\hline \multicolumn{2}{|c|}{ Beam } & Bars & $\begin{array}{l}\ell_{e} \\
(\mathrm{~mm})\end{array}$ & $\begin{array}{l}\ell_{d} \\
(\mathrm{~mm})\end{array}$ & $\begin{array}{l}L_{t c} \\
(\mathrm{~mm})\end{array}$ & $\begin{array}{l}f_{s v, c a l c}{ }^{\mathrm{b}} \\
(\mathrm{MPa})\end{array}$ & $\begin{array}{l}f_{s v, e x p}{ }^{c} \\
(\mathrm{MPa})\end{array}$ \\
\hline \multirow[t]{6}{*}{$\bar{B} 1$} & 1 & $\mathrm{R} 2$ & 50 & 97.7 & 4 & 248 & 332 \\
\hline & & R3 & 114 & & 42 & 480 & 480 \\
\hline & & R4 & 84 & & 30 & 410 & 180 \\
\hline & $1 \mathrm{R}$ & R2 & 10 & 97.2 & 62 & 51 & N/A \\
\hline & & R3 & 153 & & 20 & 480 & N/A \\
\hline & & R4 & 85 & & 16 & 420 & N/A \\
\hline \multirow[t]{4}{*}{ B2 } & 1 & R3 & 93 & 62.4 & 20 & 436 & 436 \\
\hline & & R4 & 26 & & $0^{\mathrm{a}}$ & 178 & 272 \\
\hline & $1 \mathrm{R}$ & R3 & 139 & 62.2 & 31 & 436 & 436 \\
\hline & & R4 & 45 & & 28 & 315 & 270 \\
\hline \multirow[t]{4}{*}{ B3 } & 1 & R2 & 88 & 97.1 & $42^{\mathrm{a}}$ & 433 & 378 \\
\hline & & R3 & 119 & & 15 & 480 & 480 \\
\hline & 2 & $\mathrm{R} 2$ & 27 & 96.2 & 95 & 136 & 144 \\
\hline & & R3 & 119 & & 11 & 480 & 480 \\
\hline \multirow[t]{5}{*}{ B4 } & 1 & R3 & 308 & 90.5 & 88 & 448 & 448 \\
\hline & & R4 & 128 & & $92^{\mathrm{a}}$ & 448 & 374 \\
\hline & $1 \mathrm{R}$ & R2 & 135 & 90.5 & 146 & 448 & 431 \\
\hline & & R3 & 327 & & 107 & 448 & 448 \\
\hline & & R4 & 124 & & 96 & 448 & 61 \\
\hline \multirow[t]{8}{*}{ B5 } & 1 & R3b & 129 & 91.0 & $195^{\mathrm{a}}$ & 448 & 448 \\
\hline & & $\mathrm{R} 3 \mathrm{t}$ & 39 & & 146 & 192 & N/A \\
\hline & & $\mathrm{R} 4 \mathrm{t}$ & 172 & & 17 & 448 & 448 \\
\hline & $1 \mathrm{R}$ & $\mathrm{R} 2 \mathrm{~b}$ & 196 & 91.0 & 194 & 448 & 448 \\
\hline & & $\mathrm{R} 2 \mathrm{t}$ & 35 & & 110 & 171 & N/A \\
\hline & & $\mathrm{R} 3 \mathrm{~b}$ & 16 & & 169 & 77 & N/A \\
\hline & & $\mathrm{R} 3 \mathrm{t}$ & 202 & & 21 & 448 & 448 \\
\hline & & $\mathrm{R} 4 \mathrm{t}$ & 111 & & 75 & 448 & 439 \\
\hline
\end{tabular}

${ }^{a}$ Several cracks cross the transverse reinforcing bar. The bar embedded length and the relative distance to the strain gage are not measured with the same crack. ${ }^{\mathrm{b}}$ Determined with Eq. 3.

${ }^{\mathrm{c}}$ Determined with Eq. 4 and the maximum measured bar strain in Fig. 8. 


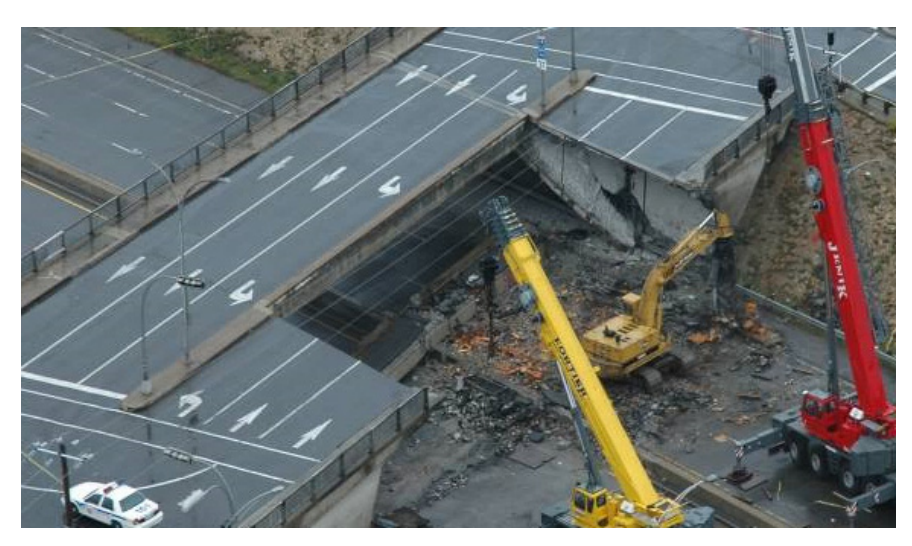




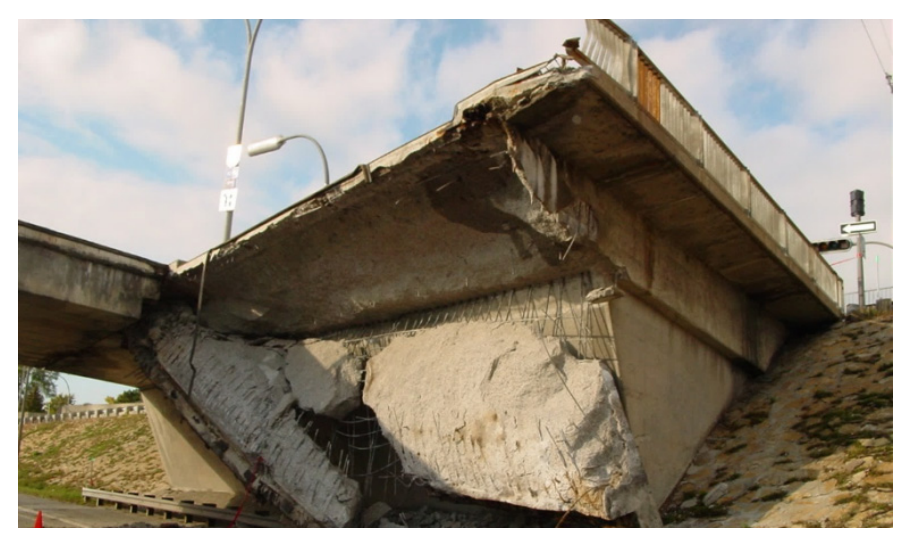




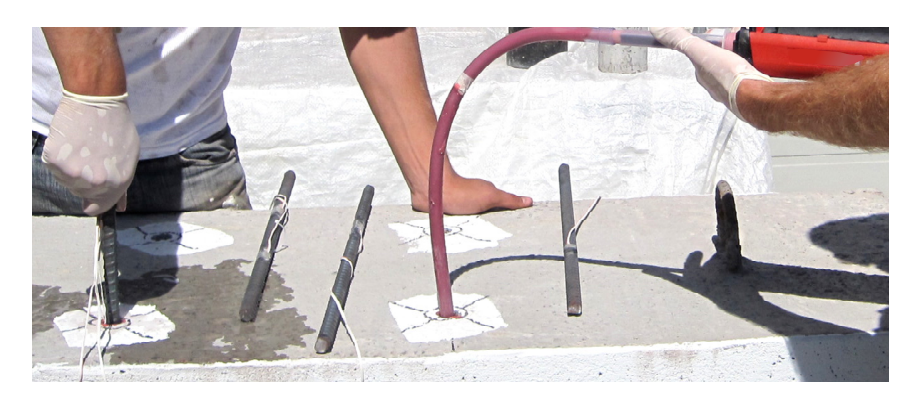

Fig $2 a$

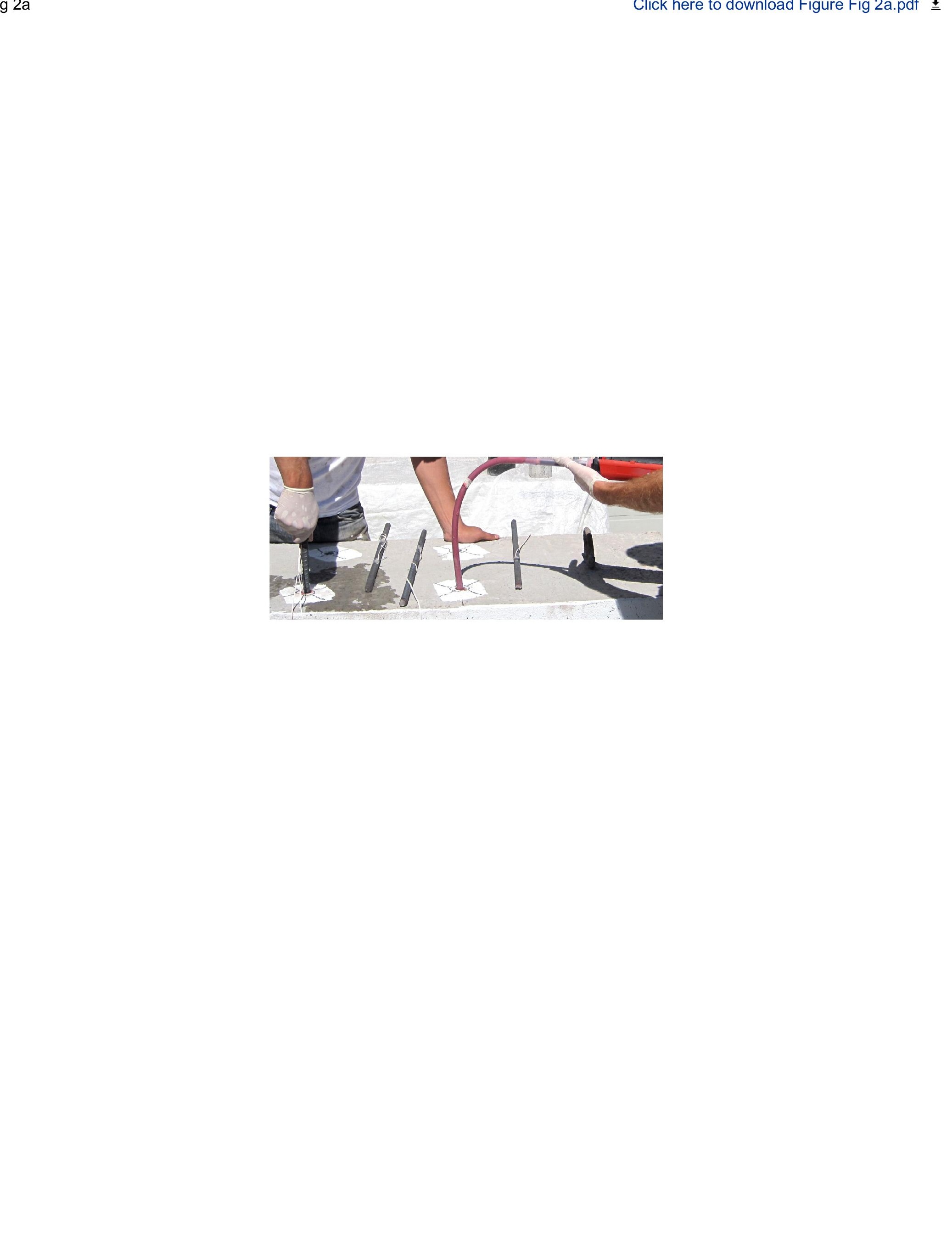


Click here to download Figure Fig 2b.pdf $\stackrel{\underline{\underline{ }}}{ }$

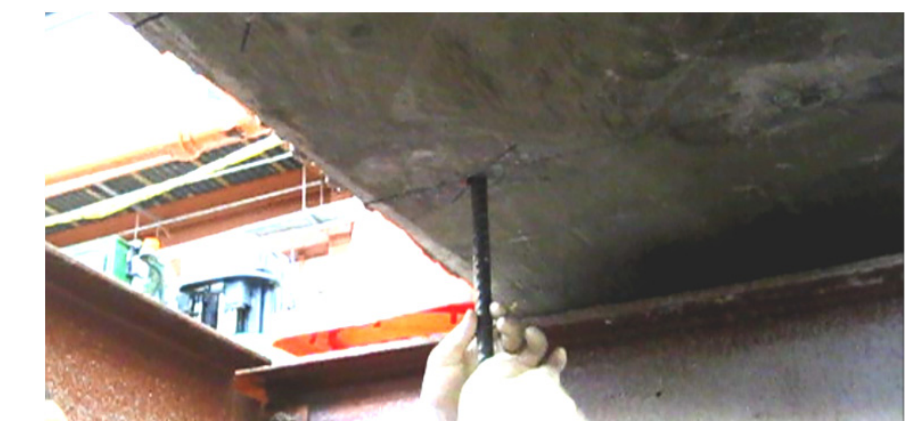

Fig $2 b$ 

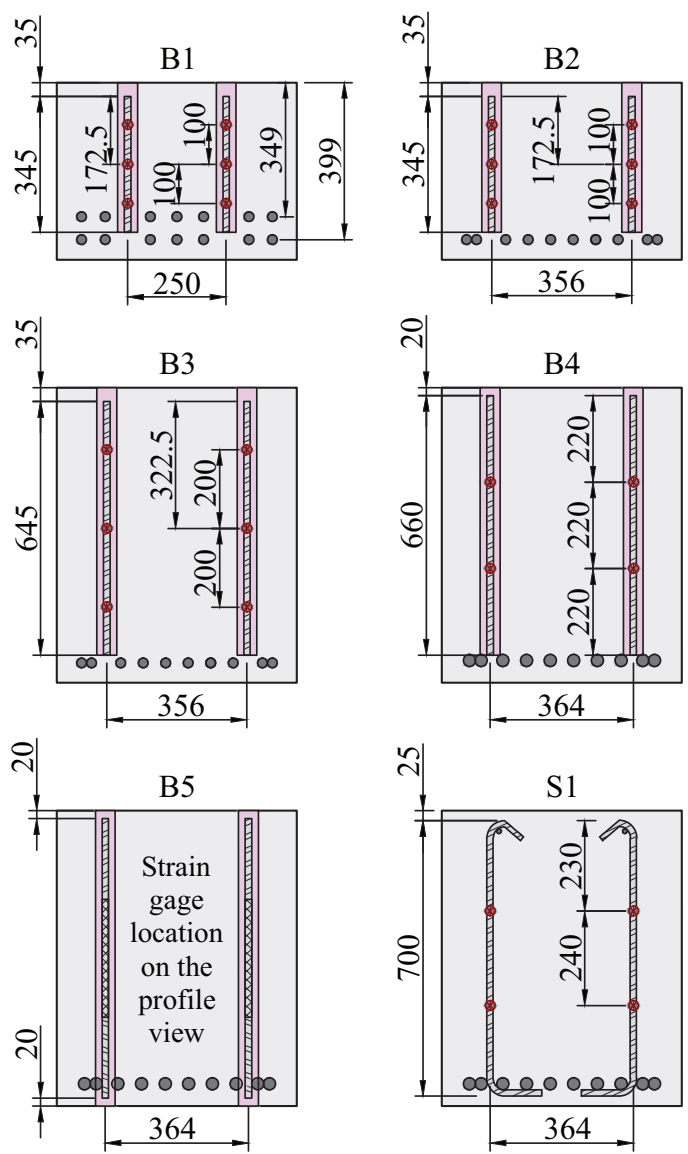


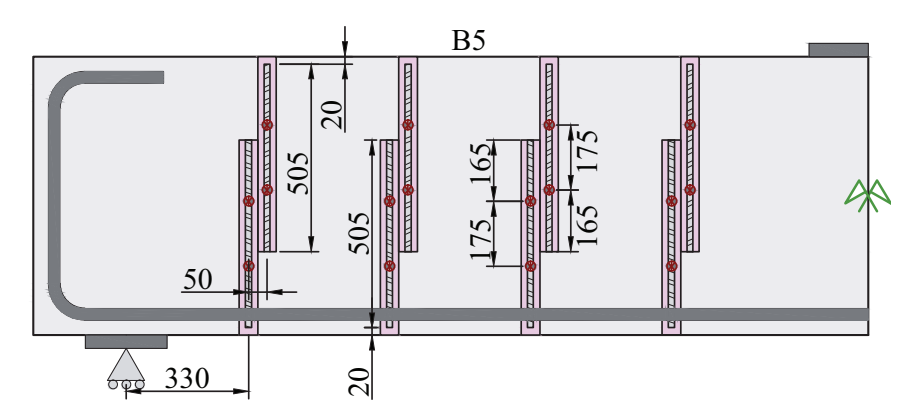

Fig $3 k$ 


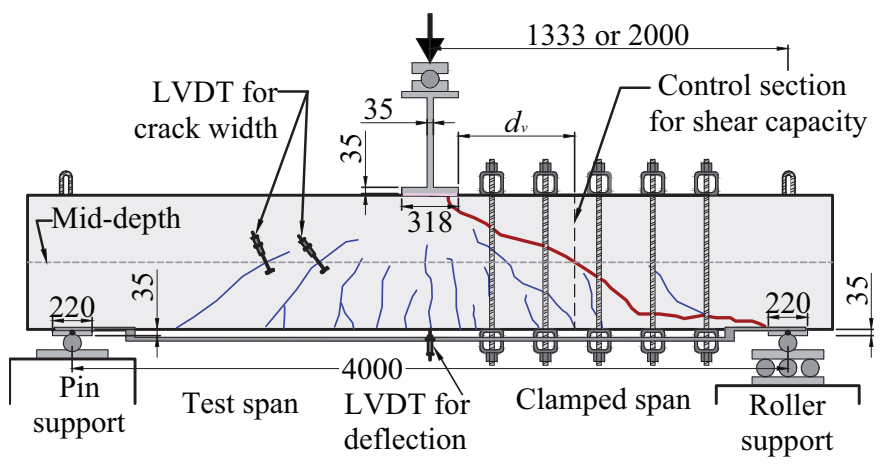



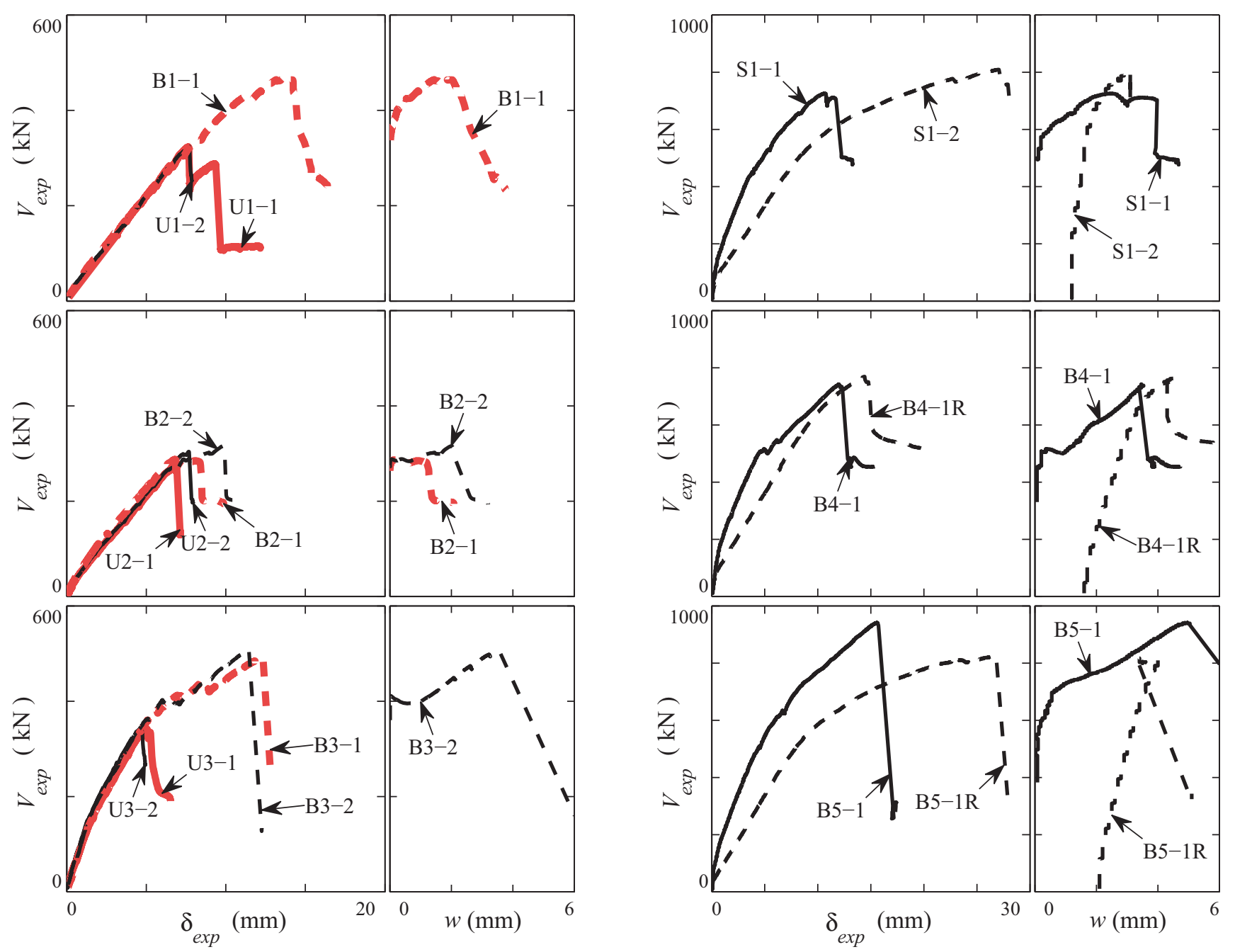


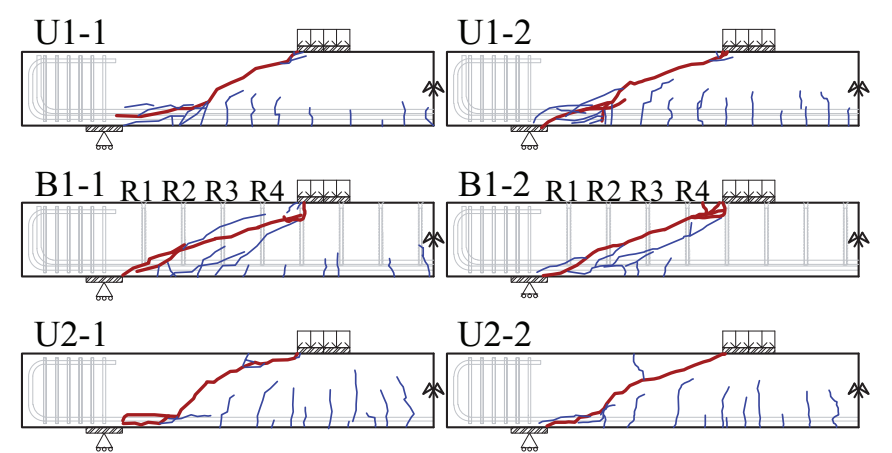

B2-1 R1 R2 R3 R4

$B 2-2$ R1 R2 R3 R4
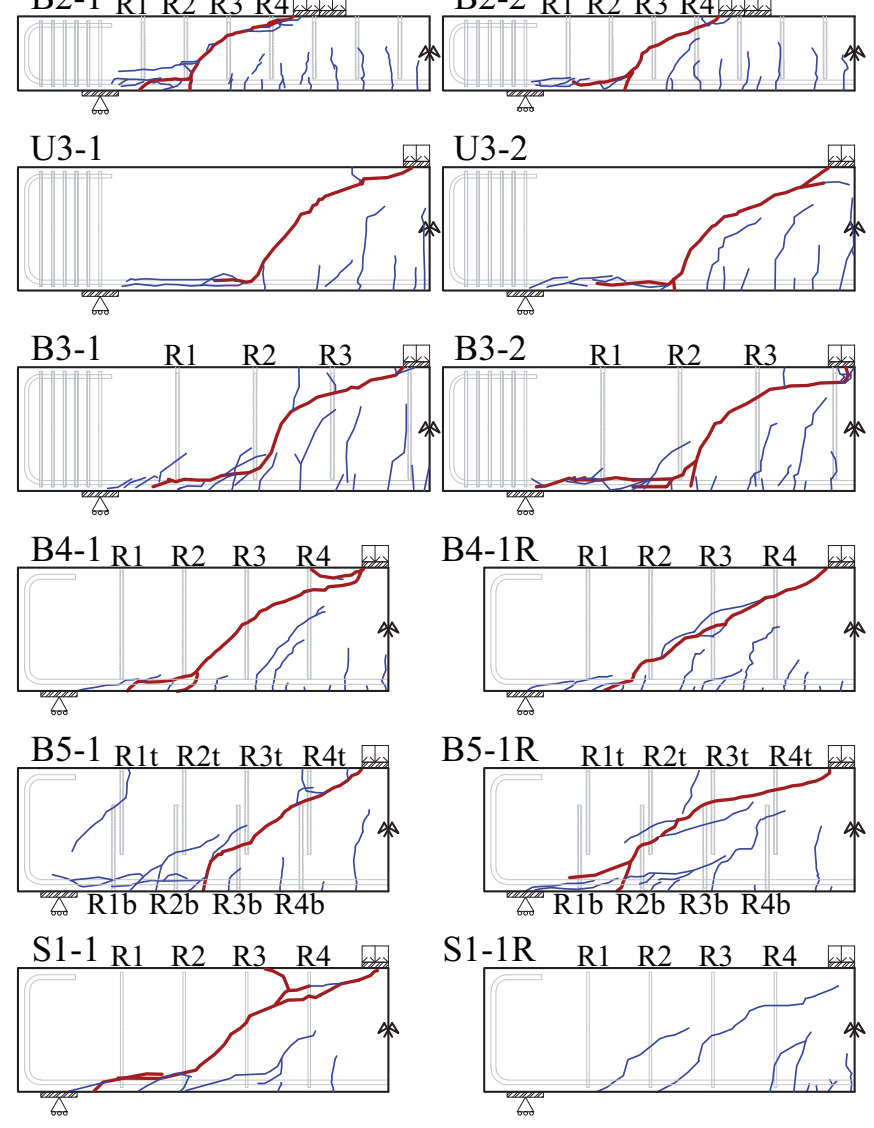


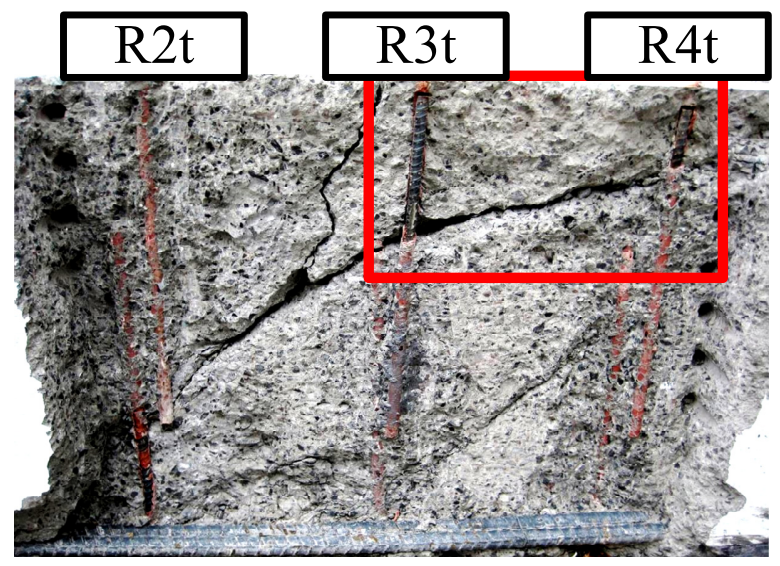




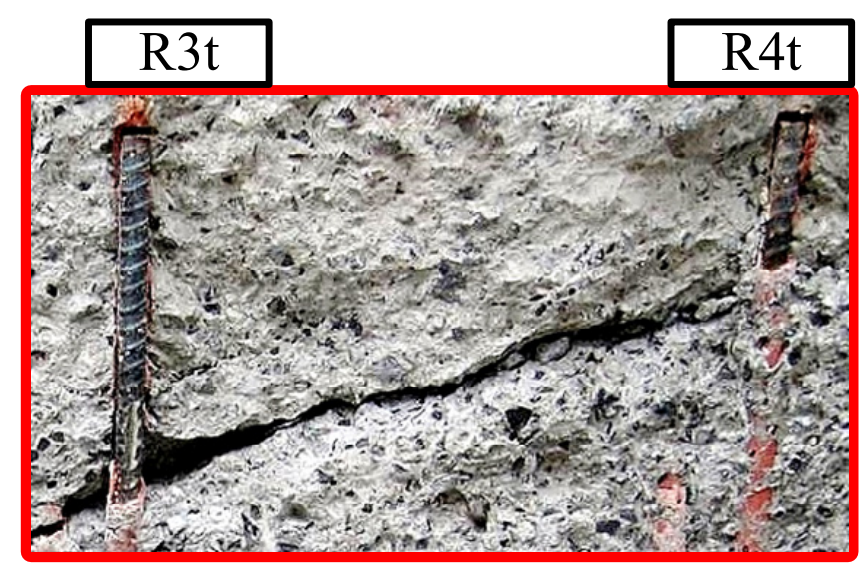

Fig $7 b$ $\mathrm{R} 4 \mathrm{t}$ 


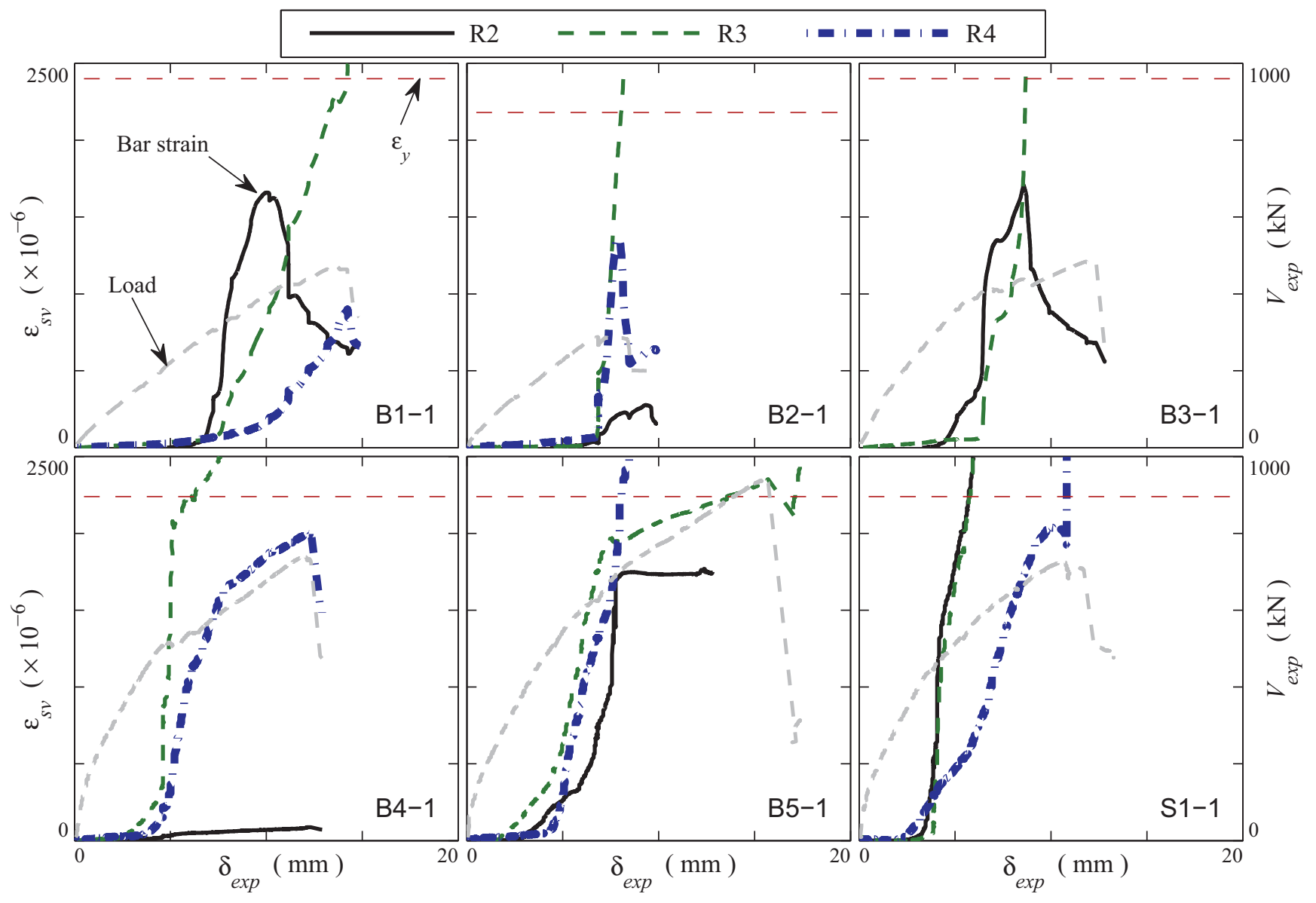




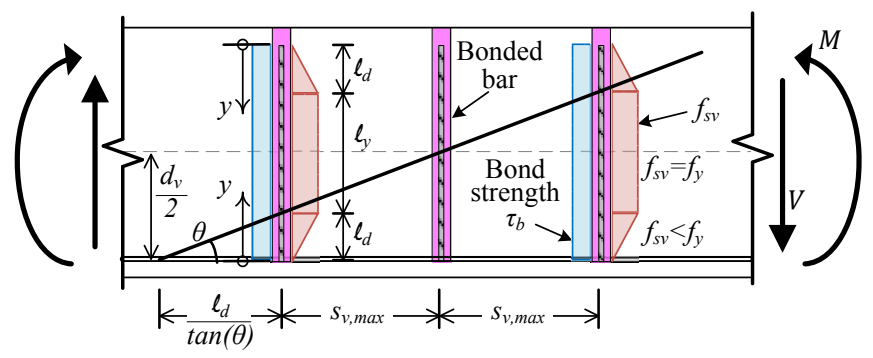




\section{Figure caption list}

2 Fig. 1. Partial collapse of south portion of Concorde Overpass due to shear failure of thick slab

3 (a) Aerial view of south portion (with permission Johnson et al. 2007) and (b) Shear failure of

4 thick slab that started near southeast corner (image by D. Mitchell)

5 Fig. 2. Installation of the epoxy bonded bars (a) from the top beam surface and (b) from the

6 bottom beam surface (image by J. Bastien)

7 Fig. 3. (a) Tested strengthened slab slices specimens (b) Profile view of beam B5 (dimensions in $8 \mathrm{~mm})$

$9 \quad$ Fig. 4. Experimental setup for reloading (R) stage (dimensions in $\mathrm{mm}$ )

$10 \quad$ Fig. 5. Load $V_{\text {exp }}$ and critical shear crack width $w$ vs beam deflection curves $\delta_{\text {exp }}$

11 Fig. 6. Cracking pattern of tested beam

12 Fig. 7. Profile cut section of beam test B5-1R (a) Overall view of internal shear crack (b) Close-

13 up of shear failure crack (image by J. Bastien)

14 Fig. 8. Strain of shear reinforcing bars near the main shear crack and applied load vs beam deflection (for beam B5-1, bars R2, R3 and R4 refer to R2b, R3b and R4t)

16 Fig. 9. Maximum bar spacing for beam with bonded shear reinforcing bars 